\title{
Short communication: The diurnal intake and behavior of dairy cows when access to a feed of consistent nutritive value is restricted
}

\author{
A. J. John, ${ }^{* 1}$ S. C. Garcia, ${ }^{*}$ K. L. Kerrisk, ${ }^{*}$ M. J. Freeman,† M. R. Islam, ${ }^{*}$ and C. E. F. Clark* \\ *Dairy Science Group, School of Life and Environmental Sciences, Faculty of Science, The University of Sydney, Camden 2570 , \\ New South Wales, Australia \\ †Tasmanian Institute of Agriculture Dairy Centre, University of Tasmania, Burnie 7320, Tasmania, Australia
}

\section{ABSTRACT}

The diurnal variation in pasture nutritive value adds a confounding factor to studies elucidating the effect of time of day on behavior. Our work separates the effect of time of day on both feeding and lying patterns for cows outdoors to enable the alignment of feeding behavior with feed management. We determined the diurnal intake patterns and behavior of dairy cows when the nutritive value of feed remained constant throughout $24 \mathrm{~h}$ in an outdoor environment, and when feed access was restricted. Nine nonlactating Holstein-Friesian cows (live weight $626 \pm 53 \mathrm{~kg}$, age $96 \pm 33$ mo; mean $\pm \mathrm{SD})$ were split into 3 groups of 3 and offered lucerne hay cubes (cube volume $32 \mathrm{~mm}^{3}$ ) ad libitum according to 3 treatments: full access (FA, feed access $24 \mathrm{~h}$ ), day access (DA, feed access between 0600 and $1800 \mathrm{~h}$ ), and night access (NA, feed access between 1800 and 0600 h). Treatments were applied to individual cows in a crossover design with 7 -d periods. During the last $4 \mathrm{~d}$ of each period, data were collected on feed intake, as well as feeding and lying behaviors. Total daily intake was greater for cows on the FA treatment (3.5\% of $\mathrm{BW}$ ) compared with the DA and NA treatments at 3.1 and $2.9 \%$ of BW, respectively. The cows with FA consumed $69 \%$ of their total intake during the day (0600-1800 h), with the greatest intake (39\%) occurring during 1200 to $1800 \mathrm{~h}$ and only $12 \%$ of intake occurring during 2400 to $0600 \mathrm{~h}$. Cows with DA consumed $56 \%$ of feed during 0600 to $1200 \mathrm{~h}$ and $44 \%$ during 1200 to $1800 \mathrm{~h}$. In contrast, NA cows consumed more feed $(74 \%)$ during the first $6 \mathrm{~h}$ period (1800-2400 h), thus maximizing lying time between 2400 and $0600 \mathrm{~h}$. The time spent lying throughout daylight periods varied between treatments; however, total daily lying time was similar across the 3 treatments. This experiment shows the feeding and lying behaviors of cows when feed quality remains con-

Received November 2, 2016.

Accepted July 21, 2017.

${ }^{1}$ Corresponding author: ajoh7559@uni.sydney.edu.au stant throughout $24 \mathrm{~h}$, which will assist the formulation of variable feed allocation strategies for future testing in both robotic and conventional milking systems. Varying the quantity of feed offered throughout $24 \mathrm{~h}$ may benefit robot utilization at night in automatic milking systems through increased feeding activity, and as we observed, is likely to have little effect on lying time or DMI, with cows readily adapting to changes in feed management. Conversely, aligning feed on offer with preferred feeding time in conventional milking systems may increase the intake of high quality pasture.

Key words: feeding behavior, lying behavior, dairy cow, ad libitum feeding

\section{Short Communication}

Understanding the interaction between feeding management and cow feeding behavior is important with the increasing prevalence of precision dairy farming technologies, such as automatic milking systems (AMS). In pasture-based AMS, where robots perform milking, dairy cows have greater freedom to choose when to access fresh pasture. As feed availability is the primary motivation for cows to return for milking (Prescott et al., 1998), offering fresh feed is the main incentive used to encourage voluntary cow traffic in pasture-based AMS (Kerrisk, 2009). However, determining the ideal feed allocation throughout $24 \mathrm{~h}$ to optimize AMS utilization is still unknown, often resulting in low robot utilization between 2400 and $0600 \mathrm{~h}$ (John et al., 2016). Managing feeding practices to complement the natural feeding behavior of dairy cows could improve production in pasture-based dairy systems. To solve this issue, we need a clear understanding of cow feeding behavior and how to manipulate it.

Cows follow a distinct diurnal grazing pattern; for example, Gibb et al. (1998) observed 5 grazing bouts per day, most occurring during daylight, and only 1 grazing bout occurring between 2200 and $0600 \mathrm{~h}$. The dusk grazing event is the longest, occupying approximately $40 \%$ of daily total feeding time (Taweel 
et al., 2004), whereas grazing at night accounts for as little as $16 \%$ of total daily feeding time (Stobbs, 1970). The dusk grazing event is also the most intense, with bite rates greater at dusk, in comparison to dawn feeding events for dairy cows (Taweel et al., 2004) and beef heifers (Gregorini et al., 2006). Gregorini (2012) outlined several factors explaining why cows follow a diurnal pattern of grazing: diurnal fluctuations in feed quality, photoperiod, predatory instincts, and satiety hormones.

Diurnal variation in feed nutritive value can influence the feeding behavior of grazing dairy cows, with dusk the most efficient time for ruminants to graze (Gregorini, 2012). Daily variation in the nutritive value of ryegrass (Lolium perenne) swards has been measured by Delagarde et al. (2000), with total soluble carbohydrates in the upper strata increasing by $30 \%$, whereas NDF and CP decreased by 6 and 8\%, respectively, between 0800 and $1900 \mathrm{~h}$. Greater DMI at dusk has also been attributed to a corresponding increase in pasture DM content (Gibb et al., 1998). This diurnal variation in pasture nutritive value adds a confounding factor to studies elucidating the effect of time of day on behavior. Feeding behavior studies with cows retained indoors circumvent this issue; however, the feeding patterns of these cows differ markedly from cows situated outdoors (O'Connell et al., 1989). Further work is required to determine the natural feeding behavior of cows situated outdoors, in the absence of the variation in feed quality present in pasture-based studies.

Studies restricting time at pasture have found cows will alter their feeding behavior to suite the feed restriction applied, feeding more intensely during the initial phase of pasture access when restricted to $8 \mathrm{~h}$ at pasture, compared with 24-h access (Clark et al., 2010). In addition, restricting access to pasture from 22 to $9 \mathrm{~h}$ reduced daily pasture intake by $12 \%$ and grazing time from 9.2 to $7.3 \mathrm{~h} / \mathrm{d}$ (Kennedy et al., 2009). If increased robot utilization at night is desired due to the tendency of cows to lie down and sleep at that time (John et al., 2016), the restriction of pasture to favor activity at these times may be a solution; however, the effect of day or night time restriction of feed on intake and behavior of cows outdoors is unknown.

In this study we determined the diurnal feeding behavior and intake patterns of dairy cows when offered a feed of consistent nutritive value. A secondary objective was to determine the effect of restricting feed access, to either day or night time, on animal behavior and intake. We hypothesized that cows restricted to feeding during the night would have reduced lying time to maintain DMI as compared with those cows restricted to feeding during the day. We also hypothesized that cows with restricted feed access would have lower intakes than unrestricted cows.

Use of animals was approved by the University of Sydney's Animal Ethics Committee (2014/753). The experiment was conducted between May 25 and June 14, 2015, at the University of Sydney research farm Mayfarm, Camden, New South Wales, Australia. The daily minimum and maximum temperatures were $4.1 \pm$ $3.0^{\circ} \mathrm{C}$ and $18.1 \pm 2.2^{\circ} \mathrm{C}$, respectively (mean $\pm \mathrm{SD}$ ). The daily relative humidity at $1500 \mathrm{~h}$ was $51 \pm 12 \%$ (mean \pm SD). Two millimeters of rain was recorded on d 12 . The light and dark cycle was approximately 10 and 14 $\mathrm{h}$ with sunrise and sunset occurring at 0700 and 1700 $h$, respectively.

Nine nonlactating, multiparous, nonpregnant, Holstein-Friesian cows $(626 \pm 53 \mathrm{~kg}$ of live weight, $96 \pm$ 33 mo old; mean $\pm \mathrm{SD}$ ) were introduced to lucerne cube feed (MultiCube Stockfeeds, Yarrawonga, Australia; cube volume $32 \mathrm{~mm}^{3}, \mathrm{DM}=88.7 \%, \mathrm{NDF}=$ $46.4 \%, \mathrm{ADF}=39.5 \%, \mathrm{CP}=18 \%, \mathrm{DMD}=58.6, \mathrm{ME}$ $=8.4 \mathrm{MJ} / \mathrm{kg}$ on DM basis; average of daily subsamples collected during the experimental period). Lucerne cube was gradually increased to ad libitum levels over a 10-d acclimatization period before the start of the experiment. Ad libitum lucerne hay was also provided during the acclimatization period with a sub-sample taken before the trial to determine nutritive value (DM $=70.1 \%, \mathrm{NDF}=51.3 \%, \mathrm{ADF}=37.3 \%, \mathrm{CP}=20 \%$, $\mathrm{DMD}=61.2 \%, \mathrm{ME}=8.8 \mathrm{MJ} / \mathrm{kg}$ on DM basis). Day 7 of the acclimatization period, cows were weighed and randomly assigned to 3 treatments ( $\mathrm{n}=3$ cows per treatment) and moved to individual pens (1 cow per pen) and lucerne hay was removed from the diet. Pens measured $30 \times 10 \mathrm{~m}$ in dimension, arranged adjacent to each other in a $2 \times 5$ grid $(60 \times 50 \mathrm{~m}$ total dimension, 10 pens total) and separated by a 2 -wire fence. Also on d 7 of the acclimatization period, a pilot study using the same 9 cows determined the approximate quantity of lucerne cubes the experimental cows could consume in a 6 -h feeding period following a 16 -h period (overnight) of fasting. Following the pilot study, the cows remained in their allocated pens and offered ad libitum lucerne cubes with lucerne hay removed from the feed allocation. Water was available ad libitum in each pen. Pen pasture surfaces were mown to $3 \mathrm{~cm}$ height on the first day of each 7-d period to ensure feed offered was the only source of DM. A lick block (Olsson's Trace Element with Copper and Cobalt; Olsson's, Yennora, Australia) was freely available in each pen.

The experiment duration was $21 \mathrm{~d}$, divided into 3 periods of $7 \mathrm{~d}$ in a $3 \times 3$ Latin square design. Cows were weighed using a Thunderbird SS1000 system (Thunderbird, Mudgee, NSW, Australia) on the first 
day of each period before the $1200 \mathrm{~h}$ feeding. Each period consisted of $3 \mathrm{~d}$ of habituation, followed by 4 $\mathrm{d}$ of data collection. Each day had 4 feeding periods (0600-1200, 1200-1800, 1800-2400, and 2400-0600 h). Treatments consisted of cows offered lucerne cubes ad libitum during all 4 feeding periods (FA; full access treatment), in feeding periods 0600 to 1200 and 1200 to $1800 \mathrm{~h}$ (DA; day access treatment), or feeding periods 1800 to 2400 and 2400 to $0600 \mathrm{~h}$ (NA; night access treatment). Cows were offered enough feed to maintain an ad libitum feeding state (minimum 10\% remaining) in all feeding periods. Feed remaining at the end of each feeding period was weighed and replenished.

A subsample of fresh feed was collected each day during the feeding period at $1200 \mathrm{~h}$ for analysis of DM content. Pre- and postfeeding feed weight was recorded at individual cow level for all feeding periods. The difference between pre- and postfeeding feed weight determined gross intake per cow for each feeding period and was converted to DMI using the DM from the corresponding days feed sample. A pilot study, consisting of 50 individual measurements of feed DM pre- and postfeeding, determined feed DM decreased by $2.5 \%$ from beginning to end of a feeding period and was included in the calculation of DMI.

Feed samples were dried at $70^{\circ} \mathrm{C}$ for $48 \mathrm{~h}$ and ground to pass through $<1 \mathrm{~mm}$ sieve. Dry matter content was calculated for each individual sample. A separate subsample of ground feed samples were used to analyze ADF (Ankom Technologies, 2014a) and NDF (Ankom Technologies, 2014b) using an Ankom ${ }^{200}$ fiber analyzer. Total nitrogen was determined by combustion (AOAC International, 1995) using a Leco FP-628 Nitrogen Determinator (Leco Corporation, St. Joseph, MI) and used to calculate $\mathrm{CP}(\mathrm{CP} \%=6.25 \times$ sample nitrogen $\%)$. Feed DMD and ME were determined using the equation reported by Oddy et al. (1983) and Primary Industries Standing Committee (2007), respectively.

Cow behavior was recorded $24 \mathrm{~h}$ per d via closedcircuit television (Mobotix M15D, Mobotix Ag, Winnweiler, Germany), with an infrared camera used for night recording. To calculate $24 \mathrm{~h}$ feeding and lying probability, behavior states were recorded at 20-min intervals (e.g., 0600, $0620 \mathrm{~h}$, and so on) with the behavior being performed at the designated time recorded. The behaviors recorded were feeding $(1=$ feeding, 0 $=$ not feeding $)$ and lying $(1=$ lying, $0=$ standing $)$. Observations were recorded for each cow through visual observation of the video footage.

To determine the effect of each feeding treatment on cow feeding and lying behavior, binomial data were fitted with the general linear mixed models procedure of Genstat version 17 for Windows (VSN International
Ltd., Hemel Hempstead, Hertfordshire, UK). The interaction between treatment and time were included in the models as fixed effects and cow included as a random effect. The probability of cows lying was directly compared between treatments. For probability of feeding, the active feeding periods for DA (0600-1200 and 1200-1800 h) and NA (1800-2400 and 2400-0600 h) were directly compared using the above model, whereas time was used as the fixed effect for analysis of the FA treatment in absence of the other 2 treatments. To calculate the total proportion of the day spent performing either feeding or lying behavior, data were fitted with the same model, with treatment as the fixed effect.

The proportion of total daily intake consumed during each of the 4 feeding periods was calculated for each cow and compared using REML variance components analysis, with the interaction between treatment and feeding period as fixed effects and period and cow as random effects. Total daily DMI was compared between all 3 treatments using REML variance components analysis, with treatment as the fixed effect and cow as the random effect.

A distinct diurnal feeding pattern occurred (Table 1). The greatest intake for cows in the FA treatment occurred at sunset (1200-1800 h), similar to observations by Taweel et al. (2004), whereas the smallest proportion of intake occurred between 2400 and 0600 h. Daily DMI per cow was greater $(P<0.001)$ for FA $(23.9 \pm 0.3$ $\mathrm{kg}$; mean $\pm \mathrm{SEM})$ compared with DA $(20.7 \pm 0.4 \mathrm{~kg})$ and NA $(19.4 \pm 0.3 \mathrm{~kg})$. These DMI, at 3.5, 3.1, and $2.9 \%$ of $\mathrm{BW}$ for $\mathrm{FA}, \mathrm{DA}$, and NA, respectively, were greater than calculated maintenance requirements, but are comparable to previous studies that offered ad libitum lucerne hay (Buchman and Hemken, 1964). The reduction in DMI for DA and NA treatments was comparable to the $17 \%$ reduction observed by PérezRamírez et al. (2009) when cows were restricted to $9 \mathrm{~h}$ of daily pasture access, compared with 22 -h access. Our results suggest cows require at least 12 -h access to feed to achieve DMI greater than $3.1 \%$ of BW per day. In line with the results presented in Table 1, offering 30 to $40 \%$ of the daily allocation after the morning milking and 60 to $70 \%$ after the afternoon milking would ensure that the largest feed allocation coincides with the period of day when feeding activity and pasture WSC levels are greatest.

Total daily feeding time decreased $(P<0.001)$ from $3.7 \mathrm{~h}$ for FA to 2.9 and $2.7 \mathrm{~h}$ for DA and NA treatments, respectively. Major feeding events within the FA treatment occurred at dawn $(1.5 \mathrm{~h})$ and dusk (2.5 h), and correspond with the observations of Gibb et al. (1998; 2 and $3.3 \mathrm{~h}$, respectively). Minimal feeding activity was observed during the 1800 to $0600 \mathrm{~h}$ period, 


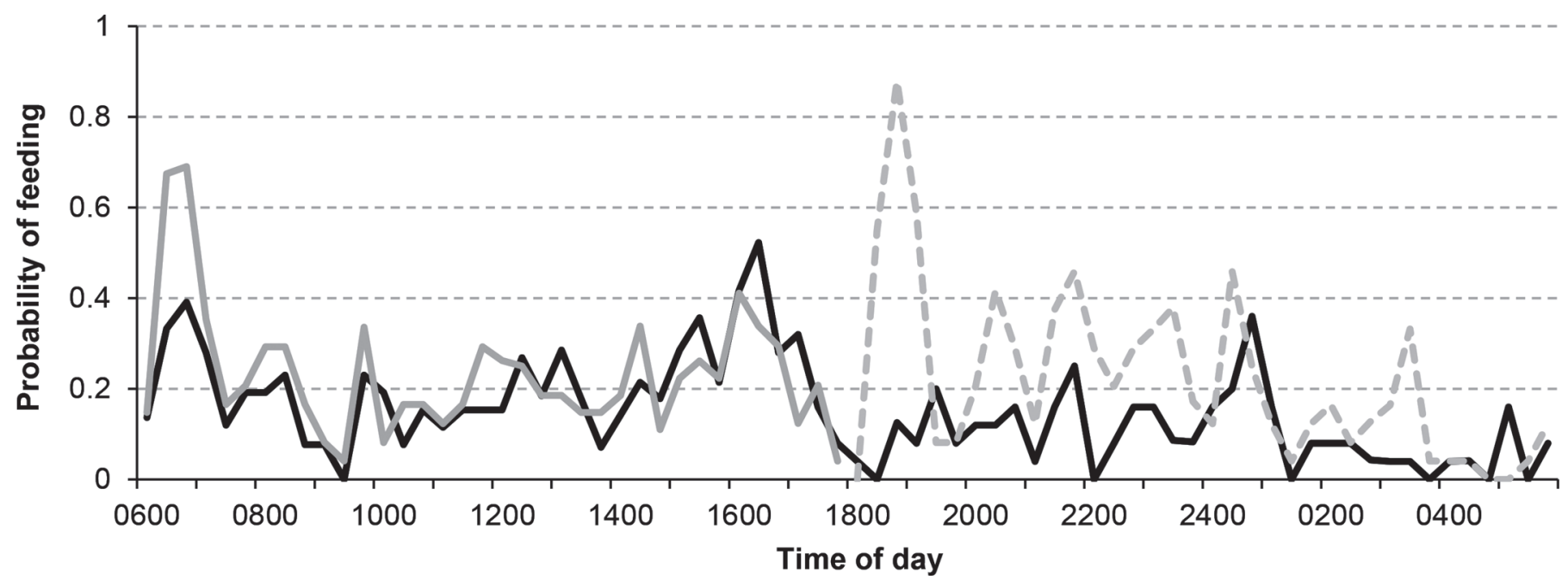

Figure 1. Probability of cows feeding throughout $24 \mathrm{~h}$ when offered lucerne hay cubes of a consistent nutritive value with full access $(24 \mathrm{~h}$, solid black line), day access (0600-1800 h, solid gray line), and night access (1800-0600 h, dashed gray line).

which is consistent with Stobbs (1970), who reported $34 \%$ of total daily grazing time occurred during this period. An interaction was observed between treatment (DA and NA) and time (duration of feed access; $P<$ 0.01) on feeding behavior (Figure 1). Cows on these 2 treatments showed an initial spike in feeding activity during the first $60 \mathrm{~min}$ of feed access, a behavior also observed by Gregorini et al. (2009) following a period of nil feed access. Beyond this initial spike, distinct feeding patterns were observed for both DA and NA treatments. Feeding activity was greatest in the first $7 \mathrm{~h}$ of feed access for the NA treatment, after which feeding activity decreased until the end of the 12-h feeding period. In contrast, feeding activity for cows with DA was more consistent across the 12 -h period, with intense feeding activity occurring in the final 3 to $4 \mathrm{~h}$ of the feeding period. Gregorini et al. (2006) observed similar feeding patterns in response to timing of fresh pasture allocation (0700 or $1500 \mathrm{~h}$ ); cows offered fresh pasture

Table 1. The proportion (mean $\% \pm$ SEM) of total DMI consumed in each feeding period

\begin{tabular}{lccc}
\hline & \multicolumn{3}{c}{ Treatment $^{1}$} \\
\cline { 2 - 4 } Feeding period $(\mathrm{h})$ & FA & DA & NA \\
\hline $0600-1200$ & $29.5 \pm 0.9^{\mathrm{a}}$ & $56.4 \pm 1.2^{\mathrm{e}}$ & $-^{2}$ \\
$1200-1800$ & $37.7 \pm 0.8^{\mathrm{b}}$ & $43.6 \pm 1.2^{\mathrm{b}}$ & - \\
$1800-2400$ & $19.6 \pm 0.9^{\mathrm{c}}$ & - & $73.5 \pm 1.2^{\mathrm{f}}$ \\
$2400-0600$ & $13.2 \pm 0.7^{\mathrm{d}}$ & - & $26.5 \pm 1.2^{\mathrm{a}}$ \\
\hline
\end{tabular}

${ }^{\mathrm{a}-\mathrm{f}}$ Significant differences $(P<0.05)$ are denoted by different superscripts.

${ }^{1} \mathrm{FA}=$ full feed access $(24 \mathrm{~h}) ; \mathrm{DA}=$ day feed access $(0600$ to $1800 \mathrm{~h}) ;$ $\mathrm{NA}=$ night feed access $(1800$ to $0600 \mathrm{~h})$.

${ }^{2}-=$ feed not offered during feeding period. at $0700 \mathrm{~h}$ spent the same duration grazing in the morning (137 min) and evening (127 min) compared with cows offered fresh pasture at $1500 \mathrm{~h}$, who then spent twice the duration (159 min) grazing in the evening compared with the morning $(76 \mathrm{~min})$. Our results show distinct times when dairy cows prefer to feed in an outdoor environment, independent of varying nutritive feed value.

We observed an interaction between treatment (FA, $\mathrm{DA}$, and NA) and time of day $(P<0.01)$ on lying probability (Figure 2). Lying probability of cows on the FA and DA treatments were similar throughout the 24-h period, with a high probability of lying between 1800 and $0600 \mathrm{~h}$. In contrast, cows on the NA treatment spent less time lying between 1800 and $2400 \mathrm{~h}$ but compensated by lying more between 0600 and $1800 \mathrm{~h}$ while also prioritizing intake during the first $6 \mathrm{~h}$ of feed access to maximize lying time between 2400 and 0600 h. Despite this, total daily lying time was similar between treatments (FA $16.1 \mathrm{~h}, \mathrm{DA} 16.4 \mathrm{~h}$, and NA 16.5 $\mathrm{h}$ ). The total daily lying time observed was comparable to studies on lying times conducted on indoor AMS (DeVries et al., 2011; Deming et al., 2013). Changes in the distribution of lying activity were similar to those observed by DeVries et al. (2005), where cows adjusted their lying patterns to suit either $2 \times$ or $4 \times$ daily feeding frequency in a housed conventional milking system (CMS). This is important when considering the changes in diurnal feeding behavior required of cows in pasture-based AMS, as feeding no longer occurs in 1 or 2 discrete allocations during the day, as with pasturebased CMS, but is distributed throughout $24 \mathrm{~h}$. This indicates the ability of cows to adapt to different feeding strategies without negative effects on lying time. 


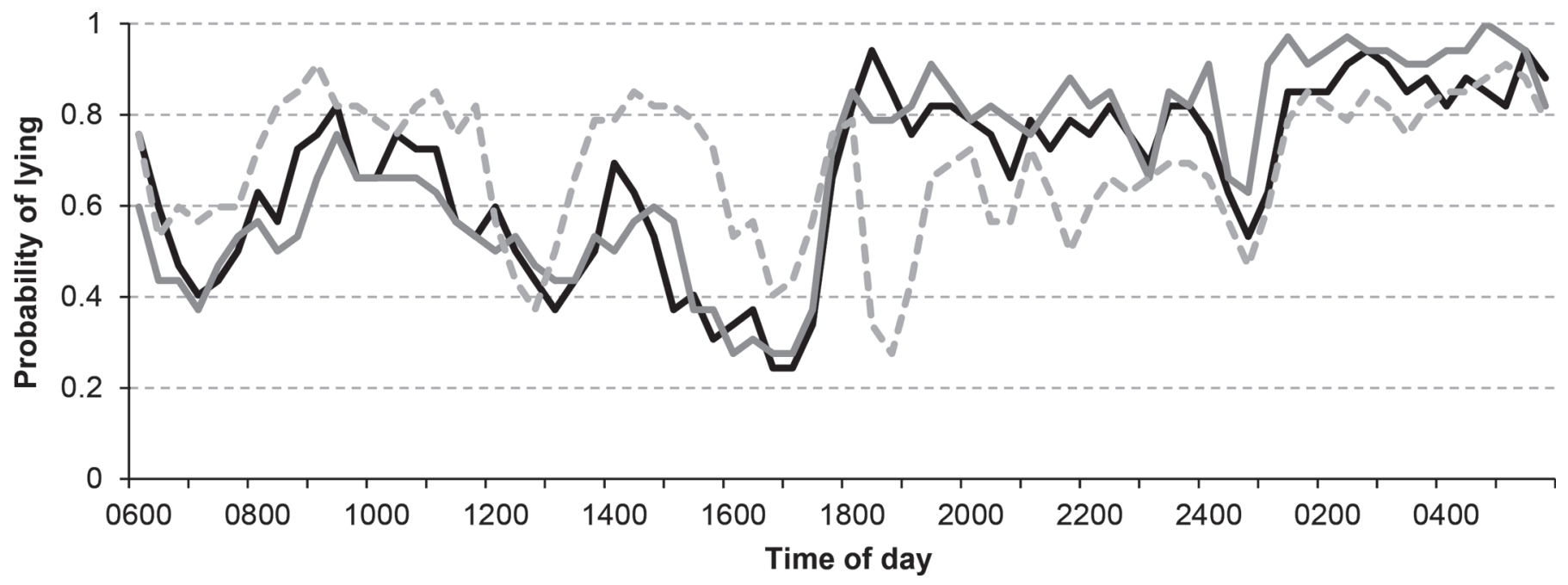

Figure 2. Probability of cows lying throughout $24 \mathrm{~h}$ when offered lucerne hay cubes of a consistent nutritive value with full access $(24 \mathrm{~h}$, solid black line), day access (0600-1800 h, solid gray line), and night access (1800-0600 h, dashed gray line).

Our work shows that cows situated outdoors follow a distinct diurnal feeding pattern when feed quality remains consistent. Further, cows can adapt their behavior to suit different feeding restrictions, without affecting DMI or lying time. Therefore, varying the amount of feed offered throughout $24 \mathrm{~h}$ is a viable option for AMS farms, where increasing feeding activity at night is desired. Conversely, aligning feed on offer with preferred feeding activity times in CMS may increase the intake of higher quality feed.

\section{ACKNOWLEDGMENTS}

The authors gratefully acknowledge the Dairy Research Foundation (Camden, Australia) for its support of the Dairy Science Group and the investors of the FutureDairy project (Dairy Australia, The University of Sydney, and DeLaval). The authors acknowledge Evelyn Hall (The University of Sydney, Camden, Australia) for her statistical input.

\section{REFERENCES}

Ankom Technologies. 2014a. Acid Detergent Fiber in Feeds-Filter Bag Technique (for A200 and A200I). ANKOM Technologies, Macedon, NY.

Ankom Technologies. 2014b. Neutral Detergent Fiber in Feeds-Filter Bag Technique (for A200 and A200I). ANKOM Technologies, Macedon, NY.

AOAC International. 1995. Official Methods of Analysis. 16th ed. AOAC International, Arlington, VA.

Buchman, D. T., and R. W. Hemken. 1964. Ad libitum intake and digestibility of several alfalfa hays by cattle and sheep. J. Dairy Sci. 47:861-864.

Clark, C. E. F., K. L. M. McLeod, C. B. Glassey, P. Gregorini, D. A Costall, K. Betteridge, and J. G. Jago. 2010. Capturing urine while maintaining pasture intake, milk production, and animal welfare of dairy cows in early and late lactation. J. Dairy Sci. 93:2280-2286. https://doi.org/10.3168/jds.2009-2907.

Delagarde, R., J. L. Peyraud, L. Delaby, and P. Faverdin. 2000. Vertical distribution of biomass, chemical composition and pepsincellulase digestibility in a perennial ryegrass sward: Interaction with month of year, regrowth age and time of day. Anim. Feed Sci. Technol. 84:49-68. https://doi.org/10.1016/S0377-8401(00)00114 -0 .

Deming, J. A., R. Bergeron, K. E. Leslie, and T. J. DeVries. 2013. Associations of housing, management, milking activity, and standing and lying behavior of dairy cows milked in automatic systems. J. Dairy Sci. 96:344-351. https://doi.org/10.3168/jds.2012-5985.

DeVries, T. J., J. A. Deming, J. Rodenburg, G. Seguin, K. E. Leslie, and H. W. Barkema. 2011. Association of standing and lying behavior patterns and incidence of intramammary infection in dairy cows milked with an automatic milking system. J. Dairy Sci. 94:3845-3855. https://doi.org/10.3168/jds.2010-4032.

DeVries, T. J., M. A. G. von Keyserlingk, and K. A. Beauchemin. 2005. Frequency of feed delivery affects the behavior of lactating dairy cows. J. Dairy Sci. 88:3553-3562. https://doi.org/10.3168/ jds.S0022-0302(05)73040-X.

Gibb, M. J., C. A. Huckle, and R. Nuthall. 1998. Effect of time of day on grazing behaviour by lactating dairy cows. Grass Forage Sci. 53:41-46. https://doi.org/10.1046/j.1365-2494.1998.00102.x.

Gregorini, P. 2012. Diurnal grazing pattern: Its physiological basis and strategic management. Anim. Prod. Sci. 52:416-430.

Gregorini, P., C. E. F. Clark, J. G. Jago, C. B. Glassey, K. L. M. McLeod, and A. J. Romera. 2009. Restricting time at pasture: Effects on dairy cow herbage intake, foraging behavior, hungerrelated hormones, and metabolite concentration during the first grazing session. J. Dairy Sci. 92:4572-4580. https://doi.org/10 .3168/jds.2009-2322.

Gregorini, P., M. Eirin, R. Refi, M. Ursino, E. Ansin, and S. A. Gunter. 2006. Timing of herbage allocation in strip grazing: Effects on grazing pattern and performance of beef heifers. J. Anim. Sci. 84:1943-1950. https://doi.org/10.2527/jas.2005-537.

John, A. J., C. E. F. Clark, M. J. Freeman, K. L. Kerrisk, S. C. Garcia, and I. Halachmi. 2016. Review: Milking robot utilization, a successful precision livestock farming evolution. Animal 10:14841492. https://doi.org/10.1017/S1751731116000495.

Kennedy, E., M. McEvoy, J. P. Murphy, and M. O'Donovan. 2009 Effect of restricted access time to pasture on dairy cow milk production, grazing behavior, and dry matter intake. J. Dairy Sci. 92:168-176. https://doi.org/10.3168/jds.2008-1091. 
Kerrisk, K. 2009. Feeding in an automated milking system. Pages 163169 in Dairy Research Foundation's 2009 Symposium, Camden. Dairy Research Foundation, University of Sydney, Camden, NSW, Australia.

O'Connell, J., P. S. Giller, and W. Meaney. 1989. A comparison of dairy cattle behavioural patterns at pasture and during confinement. Isr. J. Agric. Res. 28:65-72.

Oddy, V. H., G. E. Robards, and S. G. Low. 1983. Prediction of in vivo dry matter digestibility from the fibre and nitrogen content of a feed. Pages 395-398 in Feed Information and Animal Production: Proceedings of the 2nd Symposium of the International Network of Feed Information Centres. G. E. Robards and R. G. Packham, ed. Commonwealth Agricultural Bureaux, Slough, UK.

Pérez-Ramírez, E., J. L. Peyraud, and R. Delagarde. 2009. Restricting daily time at pasture at low and high pasture allowance: Effects on pasture intake and behavioral adaptation of lactating dairy cows. J. Dairy Sci. 92:3331-3340.

Prescott, N. B., T. T. Mottram, and A. J. F. Webster. 1998. Relative motivations of dairy cows to be milked or fed in a Y-maze and an automatic milking system. Appl. Anim. Behav. Sci. 57:23-33.

Primary Industries Standing Committee. 2007. Nutrient Requirements of Domesticated Ruminants. CSIRO Publishing, Collingwood, Australia.

Stobbs, T. 1970. Automatic measurement of grazing time by dairy cows on tropical grass and legume pastures. Trop. Grassl. 4:237244.

Taweel, H. Z., B. M. Tas, J. Dijkstra, and S. Tamminga. 2004. Intake regulation and grazing behavior of dairy cows under continuous stocking. J. Dairy Sci. 87:3417-3427. https://doi.org/10.3168/jds .S0022-0302(04)73477-3 